\title{
ORIGINAL ARTICLE \\ First record of Myotis alcathoe von Helversen \& Heller, 2001 (Chiroptera: Vespertilionidae) in Macedonia
}

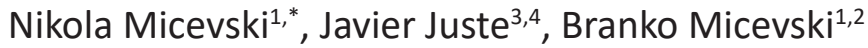

\author{
${ }^{1}$ BatLife Macedonia, Blvd. \\ Fevruarski Pohod 24/47, 1000 \\ Skopje, Macedonia \\ ${ }^{2}$ Ss. Cyril and Methodius \\ University, Faculty of Natural \\ Sciences and Mathematics, \\ Department of Animal \\ Taxonomy and Ecology, 1000 \\ Skopje, Macedonia \\ ${ }^{3}$ Estación Biológica de Doñana, \\ CSIC, Avda Americo Vespucio \\ 16, Seville 41092, Spain \\ ${ }^{4}$ CIBER de Epidemiología y \\ Salud Pública. CIBERESP, Spain
}

\begin{abstract}
Only recently separated from the Myotis mystacinus species complex, the Alcathoe whiskered bat (Myotis alcathoe) is one of the rarest tree-dwelling bats in Europe. In fact, despite the increased number of records across the continent, it is generally still poorly known. Here we present its discovery in Macedonia. A molecularly confirmed Myotis alcathoe was mist netted in the lower part of Štučka River Valley, near the Štuka village in SE Macedonia. The species is new for the bat fauna of Macedonia. This discovery brings the total number of bat species known to occur in the country to 29 . In addition, the study reports the third record of the rare Western Barbastelle bat, Barbastella barbastellus (Schreber, 1774) from Macedonia.
\end{abstract}

* Corresponding author e-mail: nikom.entomak@gmail.com

DOI: https://doi.org/10.14709/BarbJ.11.1.2018.03

Keywords: Myotis alcathoe, DNA, chiroptera, Balkans, bat species, faunistics, Barbastella barbastellus.

received: February, 13th 2018

accepted: May, 12th 2018

\section{INTRODUCTION}

The Alcathoe whiskered bat was initially discovered in Greece and Hungary, and was described based on specimens from Greece (von Helversen et al. 2001). Soon after its description, the species was also found in France (Ruedi et al. 2002), Slovakia (Benda et al. 2003), Montenegro (Benda 2004), Spain (Agirre-Mendi et al. 2004), Bulgaria (Schunger et al. 2004) and Switzerland (Stadelmann et al. 2004). During the last decade, new records followed from Germany, Poland, Albania and Turkey (Niermann et al. 2007), Romania (Jére \& Dóczy 2007), Austria (Spitzenberger et al. 2008), Czech Republic (Rehák et al. 2008), Italy (Tereba et al. 2009), United Kingdom (Jan et al. 2010), Ukraine (Bashta et al. 2011), Slovenia (Presetnik 2012), Croatia (Pavlinić et al. 2012) and Belgium (Nyssen et al. 2015). In addition to being the smallest European Myotis species, the Alcathoe whiskered bat differs from other species in the whiskered bat species complex (the Myotis mystacinus complex), by dental characteristics as well (i.e. protocone of the third upper premolar) (Dietz et al. 2009). However, in most cases, genetic analyses are necessary for a proper and unambiguous identification, particularly when new records of the species are presented.

Though there have been an increasing number of records during the past decade, the distribution of this species is still only partially understood and little is known about its conservation status. In fact, IUCN classifies it as "data deficient" (IUCN, 2017) and the European Environment Agency (EEA) describes its status as "unknown" pointing to forest clearances, use of biocides, and removal of dying and dead trees as its main threats (EEA, 2017).

\section{MATERIAL AND METHODS}

A mist netting field work session was conducted in the lower part of the Štučka river (Mt. Ogražden, SE Macedonia) on 11 October 2014. The survey was part of a wider study of the bat fauna of Mt. Ogražden during 2013-2016 for the purposes of biodiversity baseline studies preparation. Bats were captured with two mist nets $(2,5 \times 4 \mathrm{~m})$ set across the river surrounded by old Poplar trees (Populus alba L. and $P$. nigra L.). The nets were deployed half an hour before sunset and kept in place for four hours. All bats were identified, measured, weighed and photographed before being released at the same netting point. Measurements and body mass of each mist netted bat were taken using a digital caliper $( \pm 0,1 \mathrm{~mm})$ and a Pesola digital scale $( \pm 0,1 \mathrm{~g})$.

The field identification of the specimens was based on morphological characteristics given by Dietz \& von Helversen (2004) and Dietz et al. (2009). In addition, biopsy wing punches $(3 \mathrm{~mm}$ ) were taken from one questionable small 


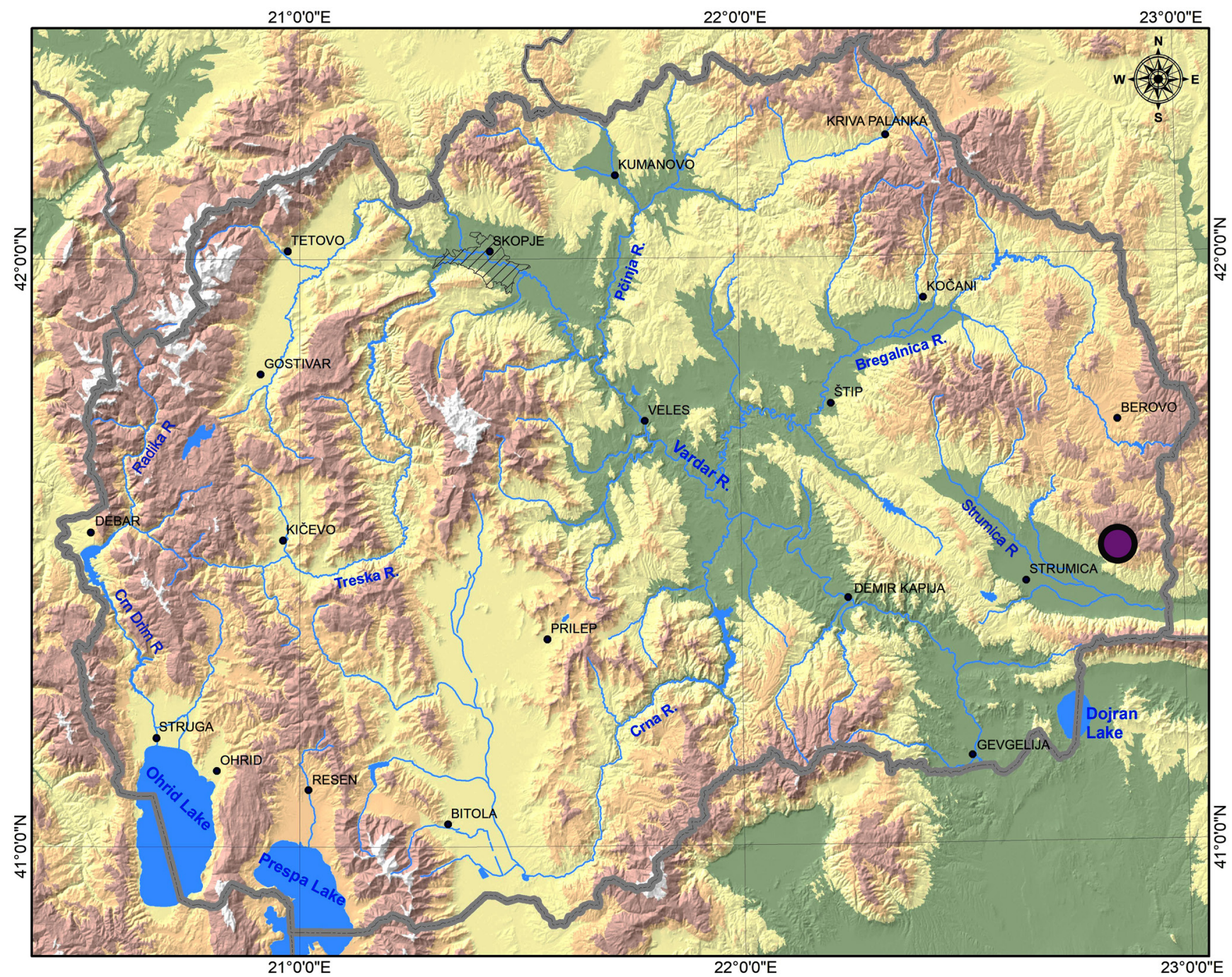

Fig. 1 - Location of the mist netted Myotis alcathoe in Macedonia.

Myotis bat and preserved in 70\% ethanol vial. Samples were later sent for DNA analyses to the Laboratory of Molecular Ecology (LEM) at the Estación Biológica de Doñana (CSIC) in Seville, Spain.

\section{Genetic analysis}

DNA was extracted from wing biopsies preserved in ethanol following Higuchi et al. (1988). A fragment of subunit 1 of the mitochondrial NADH dehydrogenase (ND1) gene was amplified using primers ND1-F2 and ND1-R (Kawai et al. 2002). The PCR mix (20 $\mu$ l final reaction volume) included $2 \mu \mathrm{l}$ of DNA extract, $1 \mu \mathrm{l}$ of each primer $(10 \mu \mathrm{M}), 0,8 \mu \mathrm{l}$ of $\mathrm{MgCl} 2(50 \mathrm{mM}), 0,16 \mu \mathrm{l}$ dNTP $(25 \mathrm{mM})$, 0,5 unit of taq-polymerase with appropriate buffer and $\mathrm{H} 2 \mathrm{O}$. Thermocycling consisted of $5^{\prime}$ initial denaturation at $94^{\circ} \mathrm{C}$, followed by 40 cycles at $94^{\circ} \mathrm{C}\left(30^{\prime \prime}\right), 52^{\circ} \mathrm{C}\left(30^{\prime \prime}\right)$ and $72^{\circ} \mathrm{C}\left(1^{\prime} 30^{\prime \prime}\right)$, with a final extension at $72^{\circ} \mathrm{C}\left(5^{\prime}\right)$. The fragment was sequenced directly from purified PCR product using an $A B I 3100$ automated sequencer (Applied Biosystems, Warrington, UK), following the manufacturer's protocols. The partial sequences were aligned and edited using the program Geneious R7 (Biomatters Ltd.) and visually inspected. For species identification purposes, the obtained sequences were compared to available sequences in the GenBank database (http://www.ncbi.nlm.nih.gov/ GenBank) using the BLAST tool. To study the phylogenetic relationships of this sample, an alignment was constructed using a selection of 13 homologous sequences of the same ND1 marker of $M$. alcathoe available in GenBank and using a M. mystacinus sample as outgroup. After selecting the best fitting substitution model using JMODELTEST-2 (Darriba et al. 2012) and the Bayesian criterion (BIC), a phylogenetic hypothesis was reconstructed using a Bayesian probabilistic criterion. The tree was obtained after three simultaneous runs of Markov chains Monte Carlo (MCMC) for $5 \times 10^{6}$ generations. Trees were sampled every 100 generations and the burn-in value was determined empirically after tree likelihood scores reached stationary. The analysis was performed using MrBAYES v.3.2. (Ronquist et al. 2012). Genetic distances between sequences and/or groups of sequences were obtained using MEGA 5.05 (Tamura et al. 2011)

\section{RESULTS AND DISCUSSION}

One small male Myotis netted in the lower part of the Štučka River $\left(41^{\circ} 28^{\prime} 16.83^{\prime \prime} \mathrm{N}, 22^{\circ} 49^{\prime} 14.13^{\prime \prime} \mathrm{E}, 340 \mathrm{~m}\right.$ a.s.l.) - Mt. Ogražden foothills, UTM-FL59 (Fig. 1) displayed morphological characteristics - particularly dentition (Fig. 2) and measurements (Table 1 ) which strongly suggested that it belonged to the Myotis alcathoe species. The sequence of around 950 bp of the ND1 fragment (Gen Bank Accession 


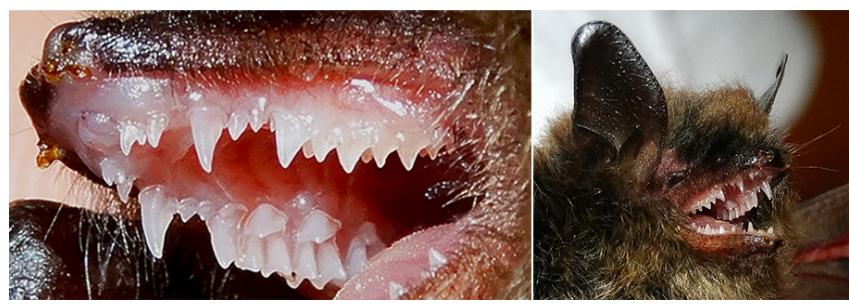

Fig. 2 - Dentition (left) and side view of the head (right) of the mist netted Myotis alcathoe in Macedonia (Photo: Nikola Micevski).

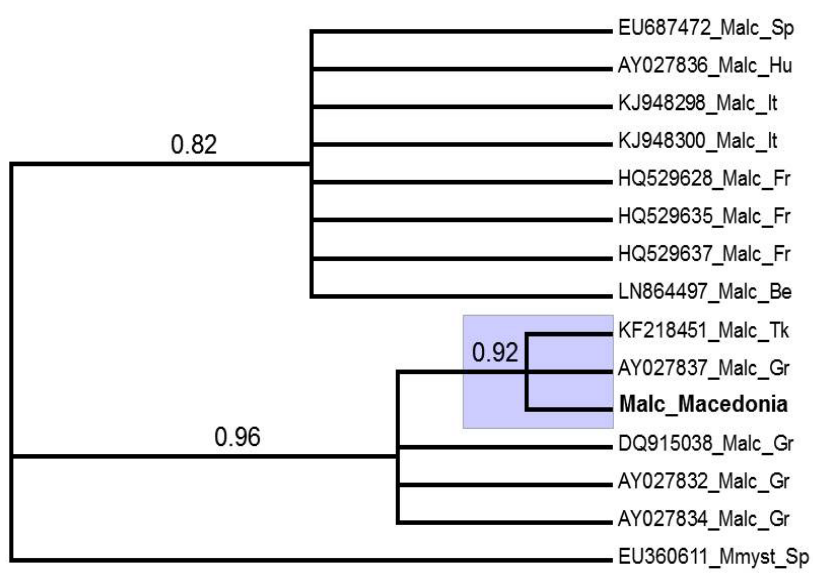

Fig. 3 - Reconstruction of the phylogenetic relationships within Myotis alcathoe based on a Bayesian analyses of a NDI mtDNA gene fragment. Values on the nodes are posterior probabilities after running 3 independent MCMC chains with $5 \times 10^{6}$ generations and using a homologous sequence of $M$. mystacinus to root the tree.

Number MG917094) showed > 95\% identity with available homologous ND1 sequences of M. alcathoe in GenBank in a BLAST comparison, indicating unambiguously that the small Myotis was in fact a $M$. alcathoe bat. The studied alignment of the ND1 fragment included 15 sequences of $800 \mathrm{bp}$ long. The best fitting selection model for the aligment was HKY85 (Hasegawa et al. 1985) that was incorporated into the Bayesian analysis in which the first 200.000 generated trees were disregarded as 'burnin'. The final Bayesian phylogenetic reconstruction indicates that the bat from Macedonia clusters undoubtly with the rest of $M$. alcathoe sequences (Fig. 3). In fact, the topology is structured in two wellsupported groups, one made up of samples corresponding to the south of the Balkan Peninsula and Anatolia and another group which includes samples from Central and Western Europe. This grouping could be also identified in a tree shown as supplementary material in a previous study on the species (Bogdanowicz et al. 2015), although the fact was not commented in that study; according to our sequences, the groups show a 1,4\% K2P distance between them and point to two possible glacial refugia in the recent evolutionary history of the species, one of them in the Balkans. The new
M. alcathoe from Macedonia clusters within the first group together with samples from Greece and Anatolia with which it shares haplotype.

This record is the first one of the Alcathoe whiskered bat in Macedonia and alongside with the latest addition of Myotis bechsteinii (Kuhl, 1817) (Budinski 2017) brings the total number of bat species known to occur in the country to 29. The closest known locality of the species is the Kresna gorge in the neighboring Bulgaria (Niermann et al. 2007) at a distance of some $40 \mathrm{~km}$ to the north-east.

During the survey $(18: 20-22: 20 \mathrm{~h})$, the temperature varied from 16 to $17{ }^{\circ} \mathrm{C}$ and the wind speed was 0 on the Beaufort scale. The Alcathoe whiskered bat was netted together with seven additional bat species: Plecotus

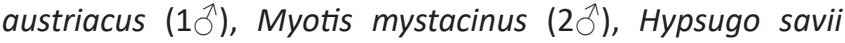
(1仓), Nyctalus leisleri (1ㅇ), Barbastella barbastellus (3仓), Pipistrellus kuhlii $(1+, 1 \precsim)$ and $P$. nathusii $(1+)$ ). The finding of $B$. barbastellus is certainly worth noting, bearing in mind that it is the third record for the country. Prior to this study this species was known only from Demir Kapija (Đulić \& Mikuška 1966) and Kriva Palanka (Stojanovski 1998); the two localities are situated in the eastern part of the country. The most recent comprehensive study of the bat fauna of Macedonia (Micevski et al. 2014) did not report this rare species, even though the surveys covered various regions and habitats, including few from Eastern Macedonia (i.e. Štip, Dojran).

The area where both the Alcathoe whiskered bat and the Western Barbastelle were discovered is highly influenced by the Mediterranean climate. The capture site (Fig. 4) is characterized by heavily degraded sub-mediterranean forest (ass. Querco carpinetum-orientalis) with scattered patches of pastures and meadows along the river, and with considerable presence of Christ's thorn (Paliurus spinachristi Mill.) and prickly juniper (Juniperus oxycedrus L.). Upstream of the river, at lower altitudes, old-grown trees such as Oriental plane (Platanus orientalis L.), common alder (Alnus glutinosa (L.) Gaertn.), and walnut (Juglans regia L.) are quite frequent. At higher altitudes, the valley becomes quite steep and wet, and, depending from the exposition, is dominated either by beech (Fagus moesiaca (Maly, Domin) Czecz.) or by oak (Quercus cerris L.) forests. A recent study on the roost ecology of $M$. alcathoe (Coronado et al. 2018) identifies the maturity of the forests and the abundance of old trunks as key factors for roost-site selection by the species. In our case, the age of the forests is mainly 40-50 years; yet, old trees are also common and most probably used for roosting as well.

This discovery of the Alcathoe whiskered bat fills the gap in its known distribution between Tepelene (Albania), Kavala (Greece) and Kresna (Bulgaria). It is expected that the species is more widely distributed in Macedonia (e.g.

Table 1 - Measurements $(\mathrm{mm})$ and body mass $(\mathrm{g})$ of the first specimen of Myotis alcathoe recorded from Macedonia.

\begin{tabular}{cccccccccc}
\hline Date & Locality & Sex & Forearm & $\mathbf{5}^{\text {th }}$ finger & $\mathbf{3}^{\text {rd }}$ finger & Thumb & Tibia & Foot & Weight \\
\hline $11-10-2014$ & Štučka River & $\widehat{\jmath}$ & 31,6 & 36,8 & 47,1 & 4,2 & 14,2 & 5,5 & 3,2 \\
\hline
\end{tabular}




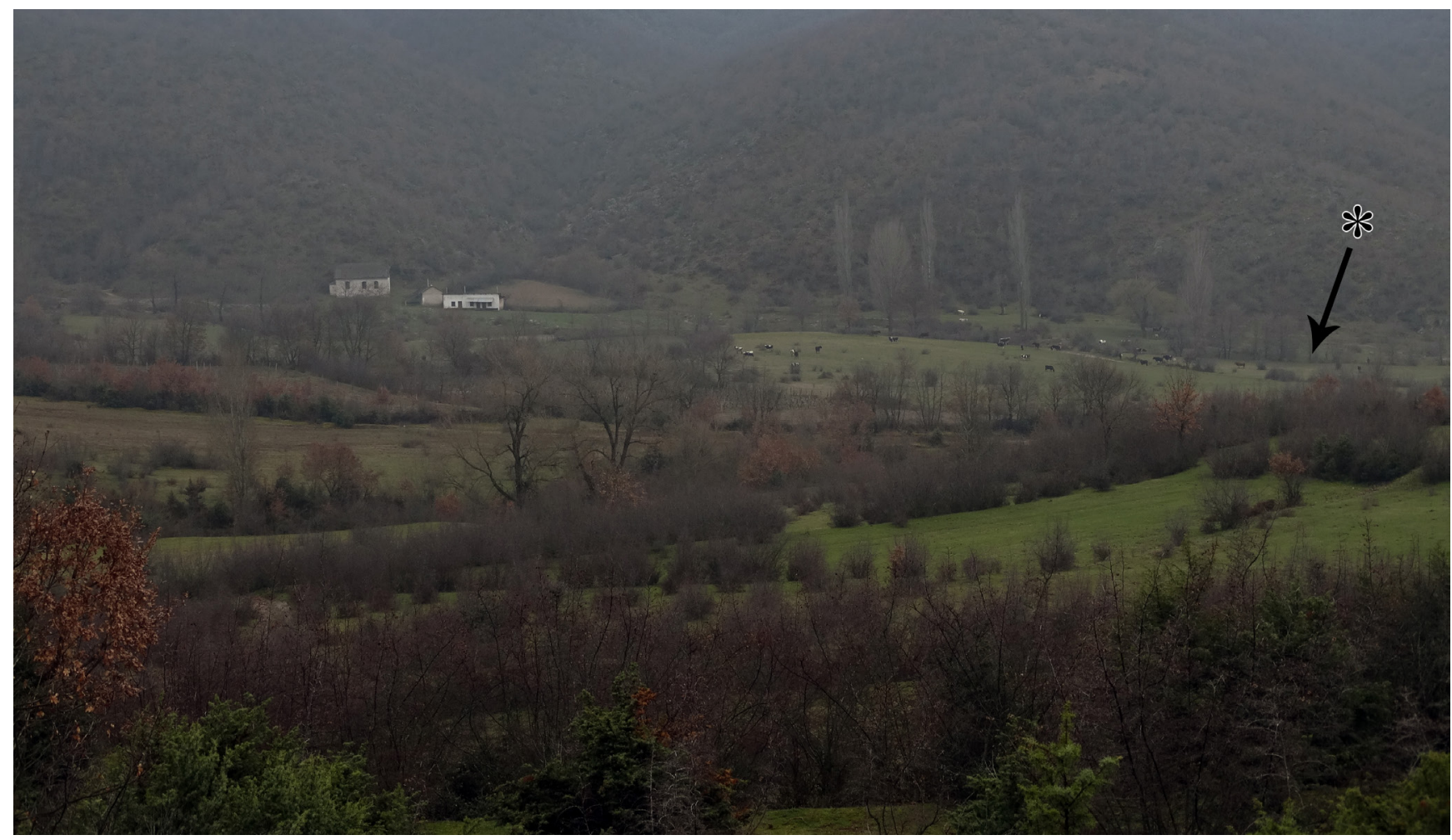

Fig. 4 - Capture site $\left({ }^{*}\right)$ of the mist netted Myotis alcathoe in Macedonia. Photo: Nikola Micevski.

Osogovski Mts., Maleševski Mts., Bregalnica River valley etc.) and further studies are necessary to confirm its status and distribution patterns in the country.

\section{ACKNOWLEDGEMENTS}

We thank to Primož Presetnik (Slovenia), Martin Cel'uch (Slovakia) and Christian Dietz (Germany) for their comments on the species determination based on morphological characteristics. We thank to Juan Luis García-Mudarra, technician of the Laboratory of Molecular Ecology of the Estación Biológica de Doñana (LEM-EBD) in Spain for the DNA extraction and sequencing, and Frieder Mayer (Museum für Naturkunde, Germany) for additional independent sequencing. We thank to Bogoljub Sterijovski (Macedonia) for his help during the field work and to Euromax Resources for supporting the survey.

\section{REFERENCES}

AGIRRE-MENDI, P. T., GARCÍA-MUDARRA, J. L., JUSTE, J. \& IBÁÑEZ, C. (2004). Presence of Myotis alcathoe Helversen \& Heller, 2001 (Chiroptera: Vespertilionidae) in the Iberian Peninsula. Acta Chiropterologica, 6 (1): 4957. https://doi.org/10.3161/001.006.0104

BASHTA, A. T., PISKORSKI, M., MISLAJEK, R. W., TEREBA, A., KORNELIUSZ, K. \& SACHANOWICZ, K. (2011). Myotis alcathoe in Poland and Ukraine: new data on its status and habitat in central Europe. Folia Zoologica, 60 (1): 1-4. https://doi.org/10.25225/fozo.v60.i1.a1.2011

BENDA, P. (2004). First record of Myotis aurascens and second record of Myotis brandtii in Montenegro. Lynx, n.s. 35: 13-18.
BENDA, P., RUEDI, M. \& UHRIN, M. (2003). First record of Myotis alcathoe (Chiroptera: Vespertilionidae) in Slovakia. Folia Zoologica, 52: 359-365.

BUDINSKI, I. (2017). The first record of Bechstein's Bat (Myotis bechsteinii (Kuhl, 1817)) in Macedonia and first data on bat fauna of the Korab Mountain. Hypsugo, II (2): 1-10.

BOGDANOWICZ, W., HULVA, P., ČERNÁ BOLFÍKOVÁ, B., BUŚ, M. M., RYCHLICKA, E., SZTENCEL-JABŁONKA, A., CISTRONE, L. \& RUSSO, D. (2015). Cryptic diversity of Italian bats and the role of the Apennine refugium in the phylogeography of the western Palaearctic. Zoological Journal of the Linnean Society, 174 (3): 635-648. https:// doi.org/10.1111/zoj.12248

CORONADO, A., FLAQUER, C., PUIG-MONTSERRAT, X., BARTHE, E., MAS, M., ARRIZABALAGA, A. \& LÓPEZBAUCELLS, A. (2018). The role of secondary trees in Mediterranean mature forests for the conservation of the forest-dwelling bat Myotis alcathoe. Are current logging guidelines appropriate? Hystrix, 28 (2): 240-246. https://doi.org/10.4404/HYSTRIX-00004-2017

DARRIBA, D., TABOADA, G. L., DOALLO, R. \& POSADA, D. (2012). jModelTest 2: more models, new heuristics and parallel computing. Nature methods, 9 (8): 772.

DIETZ, C. \& VON HELVERSEN, O. (2004). Illustrated identification key to the bats of Europe. Tübingen, Germany, 72 pp.

DIETZ, C., NILL, D. \& VON HELVERSEN, O. (2009). Bats of Britain, Europe and Northwest Africa. A \& C Black Publishers, London, United Kingdom, 400 pp. 
ĐULIĆ, B. \& MIKUŠKA, J. (1966). Two new species of bats (Mammalia, Chiroptera) from Macedonia with notes on some other bats occurring in this territory. Fragmenta Balcanica Musei Macedonici Scientiarum Naturalium, 6 (1/136): 1-13.

EEA (2017). Myotis alcathoe, European Environment Agency Report under the Article 17 of the Habitats Directive for the period 2007-2012.

HASEGAWA, M., KISHINO, H. \& YANO, T. (1985). Dating the human-ape split by a molecular clock of mitochondrial DNA. Journal of Molecular Evolution, 22: 160-174.

HIGUCHI, R., VON BEROLDINGEN, C. H., SENSABAUGH G. F. \& ERLICH, H. A. (1988). DNA typing from hairs. Nature, 332: 543-546. https://doi.org/10.1038/332543a0

IUCN (2017, May 20). Myotis alcathoe, The IUCN Red List of Threatened Species.

JAN, C.M.I., FRITH, K., GLOVER, A.M., BUTLIN, R.K., SCOTT, C.D., GREENAWAY, F., RUEDI, M., FRANTZ, A.C., DAWSON, D.A. \& ALTRINGHAM, J.D. (2010). Myotis alcathoe confirmed in the UK from mitochondrial and microsatellite DNA. Acta Chiropterologica, 12: 471-483. https://doi.org/10.3161/150811010X538043

JÉRE, C. \& DÓCZY, A. (2007). Prima semnalare a speciei de liliac Myotis alcathoe Helversen et Heller, 2001 (Chiroptera, Vespertilionidae) din România. Acta Siculica 2007: 179-183.

KAWAI, K., NIKAIDO, M., HARADA, M., MATSUMURA, S., LIN, LK., WU, Y., HASEGAWA, M. \& OKADA, N. (2002). Intra- and interfamily relationships of vespertilionidae inferred by various molecular markers including SINE insertion data. Journal of Molecular Evolution, 55: 284301. https://doi.org/10.1007/s00239-002-2326-0

MICEVSKI, N., PRESETNIK, P., MICEVSKI, B. \& CEL'UCH, M. (2014). Contribution to the knowledge of the Macedonian bat fauna. Vespertilio, 17: 103-114.

NIERMANN, I., BIEDERMANN, M., BOGDANOWICZ, W., BRINKMANN, R., LE BRIS, Y., CIECHANOWSKI, M., DIETZ, C., DIETZ, I., ESTÓK, P., VON HELVERSEN, O., LE HOUÉDEC, A., PAKSUZ, S., PETROV, B., ÖSKAN, B., PIKSA, K., RACHWALD, A., ROUÉ, S.Y., SACHANOWICZ, K., SCHORCHT, W., TEREBA, A. \& MAYER, F. (2007). Biogeography of the recently described Myotis alcathoe von Helversen \& Heller, 2001. Acta Chiropterologica, 9 (2): 361-378. https://doi.org/10.3161/17335329(2007)9[361:BOTRDM]2.0.CO;2

NYSSEN, P., SMITS, Q., VAN DE SIJPE, M., VANDENDRIESSCHE, B., HALFMAERTEN, D. \& DEKEUKELEIRE, D. (2015). First records of Myotis alcathoe von Helversen \& Heller, 2001 in Belgium. Belgian Journal Of Zoology, 145 (2): 130-136.

PAVLINIĆ, I., TVRTKOVIĆ, N. \& PODNAR, M. (2012). Preliminary data on genetics and morphometrics of Myotis alcathoe (Chiroptera, Vespertilionidae) in Croatia. Mammalia, 76 (3): 331-334. https://doi.org/10.1515/ mammalia-2012-0004
PRESETNIK, P. (2012). Descriptions of first records of Myotis alcathoe in Slovenia. Natura Sloveniae, 14 (1): 5-13.

RONQUIST, F., TESLENKO, M., VAN DER MARK, P., AYRES, D. L., DARLING, A., HÖHNA, S., LARGET, B., LIU, L., SUCHARD, M. A. \& HUELSENBECK, J. P. (2012). MrBayes 3.2: efficient Bayesian phylogenetic inference and model choice across a large model space. Systematic Biology, 61 (3): 539-542. https://doi.org/10.1093/sysbio/sys029

REHÁK, Z., BARTONICKA, T., BRYJA, J. \& GAISLER, J. (2008). New records of the Alcathoe bat, Myotis alcathoe in Moravia (Czech Republic). Folia Zoologica, 57 (4): 465469.

RUEDI, M., JOURDE, P., GIOSA, P., BARATAUD, M. \& ROUÉ, S. Y. (2002). DNA reveals the existence of Myotis alcathoe in France (Chiroptera: Vespertilionidae). Revue Suisse de Zoologie, 109: 643-652. https://doi.org/10.5962/bhl. part.79614

SCHUNGER, I., DIETZ, C., MERDSCHANOVA, D., MERDSCHANOV, S., CHRISTOV, K., BORISSOV, I., STANEVA, S. \& PETROV, B. (2004). Swarming of bats (Chiroptera, Mammalia) in the Vodnite Dupki Cave (Central Balkan National Park, Bulgaria). Acta Zoologica Bulgarica, 56: 323-330.

SPITZENBERGER, F., PAVLINIĆ, I. \& PODNAR, M. (2008). On the occurrence of Myotis alcathoe von Helversen and Heller, 2001 in Austria. Hystrix (N.S.), 19: 3-12. https:// doi.org/10.4404/hystrix-19.1-4409

STADELMANN, B., JACOBS, D.S., SCHOEMAN, C. \& RUEDI M. (2004). Phylogeny of African Myotis Bats (Chiroptera, Vespertilionidae) inferred from cytochrome b sequences. Acta Chiropterologica, 6: 177-192. https:// doi.org/10.3161/001.006.0201

STOJANOVSKI, L. (1998, 2. Kongres na biolozite na Makedonija). Second record of Barbastella barbastellus (Schreber, 1774) (Mammalia, Chiroptera) on the territory of Macedonia. Kniga na Apstrakti, Ohrid, p. 93

TAMURA, K., PETERSON, D., PETERSON, N., STECHER, G., NEI, M. \& KUMAR, S. (2011). MEGA5: Molecular evolutionary genetics analysis using maximum likelihood, evolutionary distance, and maximum parsimony methods. Molecular Biology and Evolution, 28 (10): 2731-2739. https://doi.org/10.1093/molbev/msr121

TEREBA, A., RUSSO, D., CISTRONE, L. \& BOGDANOWICZ, W. (2009, Acts of the 2nd Italian Bat Congress,). Cryptic diversity: first record of Myotis alcathoe (Vespertilionidae) for Italy. pp. 85-88.

VON HELVERSEN, O., HELLER, K.-G., MAYER, F., NEMETH, A., VOLLETH, M. \& GOMBKÖTÖ, P. (2001). Cryptic mammalian species: a new species of whiskered bat (Myotis alcathoe n.sp.) in Europe. Naturwissenschaften, 88 (5): 217-223. https://doi.org/10.1007/ s001140100225 